\title{
THE NOVEMBER MEETING IN EVANSTON
}

The five hundred ninety-sixth meeting of the American Mathematical Society was held at Northwestern University on Friday and Saturday, November 23-24, 1962. Meeting headquarters were at the Pick-Georgian Hotel in Evanston, Illinois, though registration and all the scientific sessions of the meeting were held in the Technological Institute Building. There were 151 registrants, 112 of whom were members of the Society.

The Committee to Select Hour Speakers for Western Sectional Meetings invited Albert E. Heins of the University of Michigan to address the Society. Professor Heins spoke at 2:00 P.M., Friday in Lecture Room 3 of the Technological Institute Building on the subject Axially-symmetric boundary value problems. Professor Avner Friedman presided.

Sessions for the presentation of contributed papers were held at 3:15 P.M. on Friday and 10:00 A.M. on Saturday. Presiding officers were Professors Eldon Dyer, George E. Hay, W. G. Leavitt, and Seymour Sherman.

Members of the Society were entertained at a tea on Friday afternoon by the ladies of the Department of Mathematics at Northwestern University.

J. W. T. Youngs

Associate Secretary

Bloomington, Indiana 